\title{
Inferior Vena Cava Syndrome of Uncommon Aetiology
}

\section{Xavier Jiménez-Guiu1*, Antonio Romera-Villegas², Santiago Riera-Batalla ${ }^{3}$, Francisco Javier Martí-Mestre²,} Antoni Riera-Mestre ${ }^{4}$ and Ramon Vila-Coll ${ }^{2}$

${ }^{1}$ Department of resident of Angiology and Vascular Surgery, Bellvitge University Hospital, Spain

${ }^{2}$ Department of Vascular Surgeon, Angiology and Vascular Surgery, Bellvitge University Hospital, Spain

${ }^{3}$ Department Vascular Surgeon, Angiology and Vascular Surgery, Bellvitge University Hospital, Spain

${ }^{4}$ Internist, Internal Medicina, Bellvitge University Hospital, Spain

Submission: April 08, 2019 ; Published: April 18, 2019

*Corresponding author: Xavier Jiménez-Guiu, Department of resident of Angiology and Vascular Surgery, Bellvitge University Hospital, Spain

\begin{abstract}
Background: Inferior vena cava syndrome is defined as the clinical profile caused by the occlusion of the IVC secondary to a benign or malignant process.

Case report: We report a case of a 47-year-old woman referred to the emergency department because of signs and symptoms of deep vein thrombosis of left leg. A vein eco-doppler revealed a primitive iliac left vein thrombosis. After a month, even correct anticoagulation treatment, the patient presented to the emergency department with the same symptoms in the contralateral extremity. An abdominal-CT and a pelvicMRI where performed and showed uterine myomatosis with invasion into the ilio-cava territory. The case was discussed at a multidisciplinary committee and we decided to operate the patient by exploratory laparotomy. A common hysterectomy with bilateral salpingo-oophorectomy was performed. During the dissection of the uterine corpus we appreciated that part of the uterine tumour had invaded the uterine vein and advanced into the internal iliac left vein. We performed a complete extraction of the intravenous mass without complications. Pathologic examination confirmed intravascular leiomyoma.
\end{abstract}

Conclusion: Intravascular leiomyomatosis is a rare condition with surgical resection as the only curative treatment.

Keywords: Intravenous leiomyoma; Inferior vena cava syndrome; Intravascular leiomyoma

Abbrevations: IVC: Inferior Vena Cava; LMWH: Low Molecular Weight Heparin

\section{Introduction}

We define inferior vena cava (IVC) syndrome as the clinical profile caused by the occlusion of the IVC secondary to a benign or malignant process.

\section{Material and methods}

Our patient, a 47-year-old woman referred to the emergency department because of atraumatic pain in her left leg for the past 4 days. Five years ago she underwent resection of an inguinal vascular malformation. She didn't have any other risk factor of deep vein thrombosis. The physical examination revealed a swollen left leg with pitting oedema and collateral superficial veins. Because of a high á priori probability of venous thromboembolic disease, even the D-Dimer was less than $250 \mu \mathrm{g} / \mathrm{L}$, we performed a vein eco-doppler. The analysis showed signs of a common iliac left vein thrombosis. The patient was therefore treated with LMWH at therapeutic weight-adjusted doses. After a month, she presented the same symptoms in the contra lateral extremity even correct treatment.
Due to clinical suspicion of progression of venous thromboembolic disease we performed an abdominal-CT that revealed the presence of a uterine tumor and an extensive thrombosis of the internal and common iliac left veins. The thrombosis extended inside the inferior vena cava up to $25 \mathrm{~mm}$ from the drainage point of both renal veins. This thrombosis had a heterogenic density that could correspond to recanalization areas. Due to suspicion of external compression we performed a pelvic-MRI that showed uterine myomatosis with invasion into the ilio-cava territory. The case was discussed at a multidisciplinary committee of Vascular Surgery, Gynaecology and Internal Medicine and we decided to operate the patient by exploratory mid-line laparotomy.

We procured access into the retroperitoneum space and controlled the IVC with vesseloops. We clamped the IVC just below the drainage point of both renal veins to avoid embolisms during surgical manipulation (We discard the use of a IVC- 
filter preoperatively because the vein was too large). Then a total hysterectomy with bilateral salpingo-oophorectomy was performed. During the dissection of the uterine corpus we appreciated that part of the uterine tumour had invaded the uterine vein (Figure 1) and advanced into the internal iliac vein. We controlled this portion and finished the resection of the uterus, annexes and cervix.

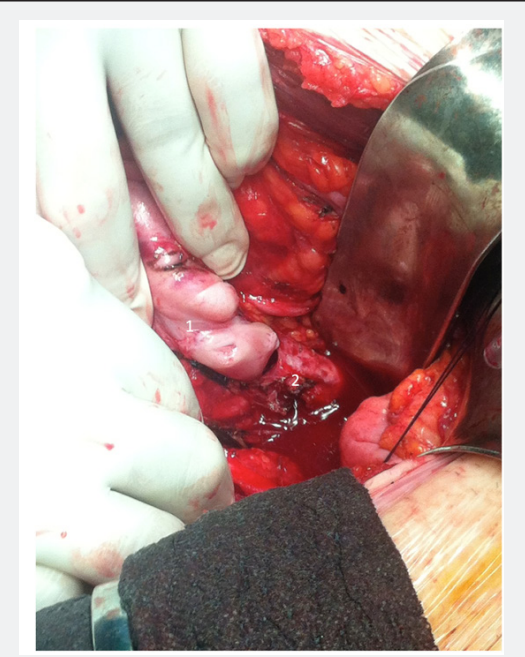

Figure 1: Intraoperative image. It can be seen that uterine tumour (1) invades uterine vein (2).

Section of the internal iliac artery was necessary in order to perform a correct dissection and control of the left iliac axis. In order to avoid right iliac venous return, instead of accessing the venous system by an IVC approach, we performed a longitudinal venotomy in the common iliac vein. We found the presence of a pearly soft mass occupying the whole venous lumen, without endothelium adhesions or associated thrombosis. The mass was sectioned in two portions and extracted with posterior iliacclamping to avoid retrograde bleeding. The remaining mass was removed and the uterine vein was tied.

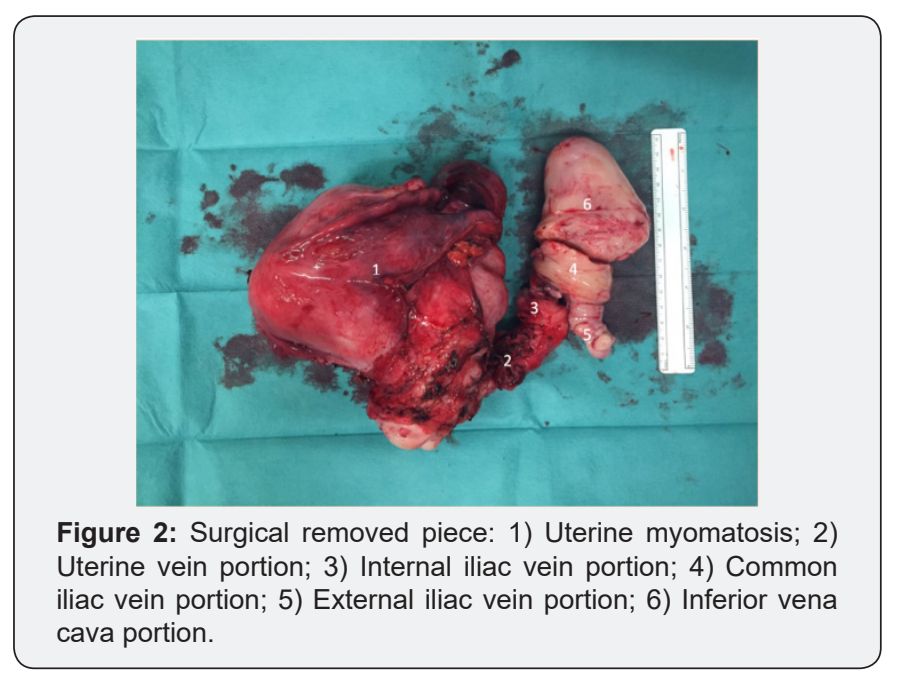

Finally, the common iliac venotomy was sutured with unabsorbable monofilament. The patient was discharged at the 7 th post operatory day without complications and with anticoagulation treatment. The pathological analysis confirmed the suspected diagnosis of intravascular leiomyomatosis of the uterus (Figure 2). At present, the patient is still asymptomatic for leg oedema. At six months we performed an abdomino-pelvic-CT that ruled out tumor recurrence and showed patency in the iliocava axis.

\section{Discussion}

Uterine myomatosis is a benign neoplasm of the smooth muscle cells of the myometrium, consisting of collagen, fibronectin and proteoglycans [1]. At present, it is the most frequent tumour among women [2]. The presentation, as invasion of the deep venous system, is a rare condition, with approximately 300 cases reported in the scientific literature [3]. Two theories are proposed as possible aetiologies: the first one states that there it is caused by a cellular proliferation of the smooth muscle of the vein wall; and the second defends that it is caused by the invasion of the vascular system by a leiomyoma from the myometrium [4]. To perform a correct diagnosis and surgical approach, it is important to perform an abdominopelvic-CT and a pelvic-MRI to precisely define the tumour's anatomy and its limits [5].

PET-CT can aid in ruling out hypermetabolic processes that could suggest malignant tumours, and define the extension. Echocardiography should be performed in order to rule out intracardiac extension. Differential diagnoses include aggressive pathology that should be discarded, like endometrial sarcoma or leiomyosarcoma [3]. Recently Guotao Ma et al. [6] in an analysis of 76 cases, they have developed a clinical stage in order to categorize the tumour progression; stage I when is confined to pelvic cavity; stage II when it hasn't reached the renal veins, stage III when it extends into right atrium; and stage IV when it reaches the pulmonary arteries6. This classification is useful in the preoperatory study in order to plan the surgery strategy.

Intravenous leiomyomatosis has to be distinguished from benign metastasizing leiomyomatosis, which involves the pulmonary dissemination of a leiomyoma without radiological or histopathological malignancy [7]; or disseminated peritoneal leiomyomatosis, which involves the proliferation of sub-peritoneal nodules composed of smooth muscle cells [8]. Treatment of choice includes the complete resection of the tumour. It entails a hysterectomy and bilateral salpingooophorectomy because of the presence of oestrogen receptors on the tumour surface associated with its growth $[1,3]$.

To avoid embolisms during surgical manipulation we clamped the IVC. This manoeuvre is not commonly described in the literature. We think that it should be performed when it's technically possible because associated thrombosis may be present. The use of a vein filter before the surgery was ruled out because the IVC's diameter was too large. Because of the high risk of bleeding we did not anticoagulate the patient during surgery. In spite of this, no thromboembolic events occurred. 
In the review of the literature, the venous approach in order to remove the mass is usually performed by venotomy of the IVC directly $[6,9,10]$. By this approach, in stage II patients, a median of $1000 \mathrm{cc}$ blood loose has been reported [6]. In our case, we successfully performed the access by a common iliac left venotomy, and thereby avoiding dissecting the contralateral iliac axis, and the IVC's reflux during the extraction of the mass. In our case the patient didn't require blood transfusion during surgery. We believe that this incision should be considered for intravascular leiomyomas localized in the infrarenal portion of the IVC.

Analogues of GnRH and aromatase inhibitors have been administered in order to reduce the size of the tumour in the preoperative care [6], or when an incomplete resection is performed [5]. This treatment has not been correctly tested and some studies cast doubt their benefit [11]. It is unclear how these patients need to be followed up. There have been reports of recurrences 39 months after surgery [3], associated with the incomplete resection of the tumour [11].

\section{Conclusion}

Intravascular leiomyomatosis is a rare condition with surgical resection as the only curative treatment.

\section{Acknowledgment}

We are grateful for Dr Espen Jiménez-Solem for his help and collaboration in the writing of the article.

\section{References}

1. Parker W (2007) Etiology, symptomatology, and diagnosis of uterine myomas. Fertil Steril 87(4): 725-736.
2. Baird DD, Dunson DB, Hill MC, Cousins D, Schectman JM, et al. (2003) High cumulative incidence of uterine leiomyoma in black and white women: ultrasound evidence. Am J Obstet Gynecol 188(1): 100-107.

3. Du J, Zhao X, Guo D, Li H, Sun B, et al. (2011) Intravenous leiomyomatosis of the uterus. A clinicopathologic study of 18 cases, with emphasis on early diagnosis and appropriate treatment strategies Hum Pathol 42(9): 1240-1246.

4. Norris HJ, Parmley T (1975) Mesenchymal tumors of the uterus. V. Intravenous leiomyomatosis. A clinical and pathologic study of 14 cases. Cancer 36(6): 2164-2178.

5. Xu ZF, Yong F, Chen YY, Pan AZ (2013) Uterine intravenous leiomyomatosis with cardiac extension: Imaging characteristics and literature review. World J Clin Oncol 4(1): 25-28.

6. Ma G, Miao Q Liu X, Zhang C, Liu J, et al. (2016) Different surgical strategies of patients with intravenous leiomyomatosis. Medicine 95(37): e4902.

7. Valde V, Conley CR, Stone WM, Collins JM, Magrina JF, et al. (2013) Update on intravenous leiomyomatosis: report of five patients and literature review. Eur J Obstet Gynecol Reprod Biol 171(2): 209-213.

8. Castro S, Dopazo C, Nadal A, Boqué-Genovard R, Zanón-Navarro V, et al. (2007) Leiomiomatosis peritoneal diseminada. Cir Esp 82(2): 125127.

9. Sogabe M, Kawahito K, Aizawa K, Sato H, Misawa Y, et al. (2014) Uterine Intravenous Leiomyomatosis with Right Ventricular Extension. Ann Thorac Cardiovasc Surg 20(Suppl): 933-936.

10. Wang J, Yang J, Huang H, Li Y, Miao Q et al. (2012) Management of Intravenous Leiomyomatosis With Intracaval and Intracardiac Extension. Obstet Gynecol 120(6): 1400-1406.

11. Li B, Chen X, Chu YD, Li RY, Li WD, et al. (2013) Intracardiac leiomyomatosis: a comprehensive analysis of 194 cases. Interact Cardiovasc Thorac Surg 17(1): 132-138.

\section{Your next submission with Juniper Publishers will reach you the below assets}

- Quality Editorial service

- Swift Peer Review

- Reprints availability

- E-prints Service

- Manuscript Podcast for convenient understanding

- Global attainment for your research

- Manuscript accessibility in different formats

( Pdf, E-pub, Full Text, Audio)

- Unceasing customer service

Track the below URL for one-step submission https://juniperpublishers.com/online-submission.php 